\title{
Microorganismos y hábitos de higiene. Estudio longitudinal en los cursos iniciales de Educación Primaria
}

\author{
José Molina (D), Esther Paños \\ Área de Didáctica de las Ciencias Experimentales. Departamento de Pedagogía. Facultad de Educación de \\ Albacete.Universidad de Castilla-La Mancha.España.jose_molina_morcillo@hotmail.com, \\ esther.panos@uclm.es
}

José-Reyes Ruiz-Gallardo

Area de Didáctica de las Ciencias Experimentales. Departamento de Pedagogía. Facultad de Educación de Albacete. Sección de Etnobiología, Botánica y Educación. Instituto Botánico de Castilla-La Mancha.

Universidad de Castilla-La Mancha. España.josereyes.ruiz@uclm.es

[Recibido: 26 abril 2020. Revisado: 27 julio 2020. Aceptado: 7 septiembre 2020]

\begin{abstract}
Resumen: El estudio analizó las ideas de los alumnos (6-8 años) sobre microorganismos e higiene básica, contrastando el aprendizaje a través de un método experimental y mediante uno más tradicional, durante la intervención y después de dos meses. Se valoró, además, el tiempo que el profesor dedica a su diferente preparación. La información se obtuvo mediante dibujos y cuestionarios a niños y a padres. Los resultados evidencian que los niños tienen, en general, una concepción limitada y negativa sobre los microorganismos, aunque sus hábitos de higiene son aceptables. La intervención mejora los conocimientos, según reflejan ambos postest y, además, se mantienen en el tiempo. Los hábitos higiénicos no variaron. No obstante, según las familias, mejora la forma de lavarse dientes y manos. No se evidenciaron diferencias en el aprendizaje entre métodos de enseñanza, pero sí en el tiempo de dedicación del maestro, que fue un $75 \%$ superior en el caso experimental.
\end{abstract}

Palabras clave: Microorganismos; Hábitos de higiene; Educación Primaria; Carga de trabajo; Dibujos.

\section{Microorganisms and hygiene habits. Longitudinal study in the early Primary Education courses}

\begin{abstract}
The study analyzes pupils' (6 - 8 years old) ideas about microorganisms and basic body hygiene. Also, it contrasts the learning, right finish and two months later, following two different teaching methods: classic vs. more practical. It values, as well, teacher workload in each proposal. Data was gathered through drawings and questionnaires to children and parents. The results show a limited and negative conception about microorganisms, although in general they have acceptable hygiene habits. Both interventions improve students' knowledge in both postests, but no differences regarding hygiene habits, in number, although families find great changes in the way of doing teeth and hands washing. However, no differences between both teaching methods have been found, while the teacher workload was $75 \%$ superior in the experimental method.
\end{abstract}

Keywords: Microorganisms; Hygiene habits, Primary Education; Workload; Draws.

Para citar este artículo: Molina J., Paños E. y Ruiz-Gallardo J. R. (2021) Microorganismos y hábitos de higiene. Estudio longitudinal en los cursos iniciales de Educación Primaria. Revista Eureka sobre Enseñanza y Divulgación de las Ciencias 18(2), 2201 doi: 10.25267/Rev_Eureka_ensen_divulg_cienc.2021.v18.i2.2201

\section{Introducción}

Los microorganismos son seres vivos microscópicos, que pueden hallarse en todos los ecosistemas de la Tierra (Harvey, Champe y Fisher 2008), y que son capaces de mantener el equilibrio de las actividades biológicas en la biosfera (Brooks, Carroll, Butel, Morse y Mietzner 2011). Además, tienen importantes aplicaciones en medicina, biotecnología, agricultura, protección del medio ambiente, producción de alimentos y bebidas, etc., por lo que autores como Byrne (2011), lo consideran como un contenido de particular relevancia para los escolares. 
Así, este trabajo realiza una intervención experimental en las aulas de $1^{\text {er }}$ y $2^{\circ}$ curso de Educación Primaria, contrastando con un grupo control que aprenderá mediante método tradicional, y evalúa longitudinalmente bajo la hipótesis de que aprenderán más y a más largo plazo aquellos que desarrollan un aprendizaje más activo.

\section{Fundamentación teórica}

\section{Los microorganismos}

Su estudio se origina en 1674, cuando Anton van Leeuwenhoek observó por primera vez protozoos y bacterias en un microscopio. Actualmente se conocen miles de especies de microorganismos, algunos capaces de sobrevivir en hábitats extremos. En la naturaleza realizan funciones indispensables como la descomposición de la materia orgánica o intervienen en ciclos biogeoquímicos (Hernández 2016). Más del 50\% de nuestras células son microbios (Sender, Fuchs y Milo 2016), entre ellos, la microbiota intestinal, que ayuda al proceso digestivo de los alimentos y previene la colonización de patógenos (Rubio, García y Cardona 2017). Además, cada vez es más frecuente su uso en la elaboración de alimentos (Rosa, Prieto y Navarro 2011) y de sustancias químicas (metano, vitaminas, antibióticos, insulina, etc.). Pero también los hay causantes de enfermedades, aunque suponen una mínima proporción respecto al total.

\section{Higiene y salud escolar}

Salud, según la OMS (1948) es: "Un estado de completo bienestar físico, mental y social, y no simplemente la ausencia de enfermedad". Por otro lado, la higiene es el conjunto de conocimientos y técnicas que debemos llevar a cabo para el control de los factores que puedan afectar negativamente sobre la salud (Higashida 2013). La niñez es la mejor etapa para aprender comportamientos higiénicos y de salud, ya que es más probable que se apliquen en la vida adulta. Además, los aprendizajes escolares sobre higiene pueden trasladarse al entorno familiar (Pradhan, Mughis, Ali, Naseem y Karmaliani 2020). Por todo ello, la escuela ofrece la oportunidad para sentar las bases de formación en higiene y en hábitos saludables (Salas 2008; Öncü et al. 2019) y estas enseñanzas deben estar inmersas en todo su planteamiento curricular (Frías 2002), en forma de Educación para la Salud.

\section{Microorganismos y Educación para la Salud en el currículum}

En el Real Decreto 126/2014 (BOE 2014), aunque el término microorganismo no aparece ni en primer ni en segundo curso, podría incluirse en el bloque 3 de Ciencias de la Naturaleza: "Los seres vivos". Además, en los estándares de aprendizaje encontramos "otros reinos". En el Decreto 54/2014 (DOCM), en los cursos $1^{\circ}$ y $2^{\circ}$, bloque 3, aparece la diferenciación entre "seres vivos e inertes", donde los microorganismos encajarían perfectamente. En el bloque 2: "El ser humano y la salud", se trabajan aspectos relacionados con hábitos de prevención de enfermedades, prácticas saludables e higiene personal. Ya en $3^{\text {er }}$ curso, Bloque 3 , encontramos por primera vez una referencia hacia hongos y bacterias. También a "otros reinos". En $5^{\circ}$ y $6^{\circ}$ se habla de una "Clasificación por niveles de la materia viva: virus, bacterias, protoctistas, hongos, plantas y animales". Los virus aparecen incluidos, aunque todavía hay debate sobre si son o no seres vivos.

\section{Enseñanza de las ciencias en Educación Primaria: método tradicional y experimental}

El primer intento de incluir las ciencias en los currículos escolares fue a mediados del siglo XIX en una escuela inglesa, utilizando el método Pestalozzi, basado en enseñar a observar los objetos (Sánchez, Bernal, García-Estaño, Guzmán y Valcárcel 2006). En España se introducen en el currículo a principios del siglo XX, con las llamadas "Lecciones de cosas" (Martí 2012). Para Rivero, Martín, Solís y Porlán (2017) el modelo didáctico tradicional, basado en la memorización mecánica de los contenidos explicados por el profesor y donde el único mediador en las relaciones en el aula es el libro de texto, continúa siendo uno de los más utilizados. 
Los métodos alternativos, como el de investigación en la escuela, se basan en proponer problemas que tengan sentido para los alumnos, construyendo sus propias ideas mediante el contraste consciente entre las propias y la información obtenida por diferentes vías (Rivero et al. 2017). Los alumnos participan activamente en su proceso de aprendizaje científico, extrayendo información a partir de la experimentación. El trabajo experimental es considerado una de las actividades más importantes en la enseñanza de las ciencias ya que (Jiménez, Caamaño, Oñorbe, Pedrinaci y Pro 2003): motiva al alumnado, proporciona un conocimiento vivencial de muchos fenómenos, ayuda a la comprensión de objetos, fomenta el trabajo en equipo, desarrolla actitudes y aplica normas propias del trabajo experimental (planificación, orden, limpieza, seguridad, etc.).

Además, para Mora (2013), los niños no aprenden si no encienden su curiosidad, y esta aumenta al observar o experimentar con cosas, situaciones o procesos poco conocidos (Cañal, García-Carmona y Cruz 2016). Sin duda, el docente es pieza clave para lograrlo.

No obstante, hay defensores de la enseñanza más guiada, más instructiva. Kirschner, Sweller y Klarck (2006) sostienen, apoyándose en la arquitectura cognitiva humana, que aprendemos mejor de otros, adquiriendo conocimientos para después aplicarlos, que con métodos basados en el descubrimiento, constructivistas o los basados en problemas. Para ellos, estos formatos poco guiados producen una sobrecarga cognitiva que impide un aprendizaje adecuado. Investigaciones posteriores lo apoyan (Matlen y Klahr 2013, Chase y Klahr 2017), obteniendo siempre mejores resultados los niños que aprendían con instrucción directa.

\section{Estado de la cuestión}

A continuación, se recogen estudios llevados a cabo en educación primaria, y que están relacionados con las concepciones y enseñanza de los microorganismos, la higiene o la salud.

Un estudio reciente en el ámbito español (Ballesteros, Paños y Ruiz-Gallardo 2018), con alumnos de entre 8 y 11 años, determinó que los niños tenían concepciones bastante limitadas y negativas sobre los microorganismos. La mayoría los ubicaban en el cuerpo humano, en sitios sucios y en el suelo. Su función se asociaba, sobre todo, a enfermedades e infecciones. Resultados similares obtienen Dominguez et al. (2018) en Brasil con niños de 4 a 6 años, en un museo de ciencias y una guardería, tras la aplicación de una secuencia didáctica. Conceptualizaron a los microorganismos con forma similar a los insectos, y mostraron que entienden la idea de escala y la necesidad de instrumentos de aumento para su observación.

Scalas et al. (2017) realizaron el proyecto "Microbiological@mind", en forma de talleres escolares prácticos con niños de 9 a 11 años, en Italia. Sus objetivos: la promoción del interés científico, el fomento de comportamientos que ayuden a tener un estilo de vida más seguro, la prevención de infecciones microbianas y el uso responsable de antibióticos. Evaluaron la experiencia mediante un cuestionario sobre el conocimiento del tratamiento contra las infecciones. Los resultados en el pretest fueron bastante pobres, pero, tras la intervención, sus conocimientos habían mejorado de forma significativa. Nuevamente en España, Ruiz-Gallardo y Paños (2017), contrastaron los aprendizajes sobre conceptos de microorganismos tras una intervención experimental y otra tradicional, en alumnos de $2^{\circ}$ y $6^{\circ}$ curso. Los resultados mostraron varios conceptos erróneos, una visión limitada y negativa de los microorganismos, que procedía principalmente del aprendizaje no formal. Cuando se les preguntó acerca de los beneficios, la mayoría coincidía en su uso como forma de protección contra otros microorganismos perjudiciales o enfermedades. Pocos sobre su uso industrial o alimenticio. No se encontraron diferencias en el aprendizaje entre los métodos contrastados.

Choi y Hong (2014) investigaron las concepciones de niños de $5^{\circ}$ y $6^{\circ}$ curso (en Corea del Sur) sobre los ambientes en los que habitan los microorganismos. La mayoría los asociaba con animales pequeños y/o plantas. El hábitat más descrito: el suelo (81.10\%). Faccio et al. (2013) realizaron una campaña para mejorar los conocimientos de los niños sobre hábitos saludables, corregirlos en el contexto de la 
seguridad alimentaria y mejorar la comprensión sobre microorganismos y sus funciones. Se comparó un enfoque de enseñanza teórico y práctico. Más de un cuarto de los niños representó los microorganismos con forma humanoide y solo el 11\% los contextualizó en el cuerpo humano. Tras su experiencia, obtuvieron mejores resultados en el grupo práctico.

Byrne (2011) evaluó los conocimientos sobre microorganismos de escolares (7-14 años), en Inglaterra. La percepción de los niños era muy negativa. Básicamente, los consideraban como causantes de enfermedades. Solo destacan la producción de yogur como aplicación beneficiosa. El estudio de Deniz y Sahin (2010) en Turquía es muy similar. El 53\% de los participantes definió a los microorganismos como suciedad, contaminantes y dañinos, aunque más de un tercio no podía dar ejemplos. A la mayoría la palabra microbio o microorganismo le evocaba sentimientos negativos. Las principales fuentes de este aprendizaje fueron los programas de radio, televisión y las noticias.

Como se observa, a pesar de su importancia, la mayoría de los estudios hallan que los conocimientos de los escolares sobre los microorganismos son escasos y negativos. Ello hace todavía más importante su correcta enseñanza desde la escuela, y con las metodologías más adecuadas. Se observa, además, que no se han estudiado niños de esta edad en España y que las intervenciones publicadas ofrecen resultados inmediatos tras la intervención, sin comprobar cómo es el aprendizaje pasado el tiempo. Ninguno evalúa la diferencia de esfuerzo temporal del profesor, como pretende el presente trabajo.

\section{Objetivos}

Los objetivos planteados son:

- Evaluar la percepción de los niños (6-8 años) sobre los microorganismos.

- Analizar sus hábitos de higiene.

- Contrastar dos metodologías de aprendizaje.

- Evaluar el tiempo de preparación que conllevan ambas metodologías.

\section{Método}

\section{Diseño de la investigación}

Es un estudio cuasiexperimental, con diseño pre/postest inmediato-2 meses después, y con grupo control y experimental. La obtención de datos se realiza mediante cuestionarios y dibujos.

\section{Participantes}

Se seleccionaron mediante muestreo no probabilístico por conveniencia. Pertenecen a un colegio concertado del centro de la ciudad de Albacete, y a un entorno socioeconómico medio-alto. Los grupos estaban confeccionados y se asignó grupo experimental o control, de forma aleatoria (Tabla 1). En el análisis final se excluyeron dos niños del grupo experimental y cinco del control, debido a su ausencia en alguna de las pruebas.

Tabla 1. Distribución de participantes por grupo (control y experimental), curso y sexo.

\begin{tabular}{|l|c|c|c|c|c|}
\hline & \multicolumn{2}{|c|}{ Control } & \multicolumn{2}{c|}{ Experimental } & \\
\hline Curso & Masculino & Femenino & Masculino & Femenino & Total \\
\hline $1 .^{\circ}(6-7$ años $)$ & 16 & 13 & 17 & 13 & 59 \\
\hline $2 .^{\circ}(7-8$ años $)$ & 8 & 20 & 8 & 19 & 55 \\
\hline Total & 24 & 33 & 25 & 32 & 114 \\
\hline
\end{tabular}




\section{Instrumentos de recogida de información}

Los datos se han recogido mediante dibujos y cuestionarios individuales, en tres momentos: antes de la intervención (marzo), al finalizarla (abril) y pasados dos meses (junio). También se realizó un cuestionario a las familias, al terminar la intervención.

Como en Faccio et al. (2013) y Byrne (2011), se entregó a los alumnos una ficha en la que debían dibujar un microorganismo en un lugar en el que pudieran encontrarlo. Se completó con dos preguntas abiertas para ayudar en su interpretación, extraídas de Ballesteros et al. (2018): "Escribe todo lo que sepas acerca de los microbios", "¿Dónde has oído hablar de los microbios?". El análisis de dibujos se ha centrado en la forma que dieron a los microorganismos, usando las categorías propuestas por los mismos autores, añadiendo una: "Forma de extraterrestre".

Seguidamente, realizaron un cuestionario de 22 ítems, extraídos de HICORIN: Higiene Corporal Infantil (Moreno 2015), de los que se analizaron 19, que incluyen aspectos sobre los microorganismos y hábitos de higiene (Tabla 2). Las cuestiones consistían en marcar una o más opciones, tres de ellas eran abiertas y en cinco se permitía la opción de argumentar su elección.

Finalmente, para averiguar la repercusión de la intervención/clase ordinaria en los hábitos del alumno, se entregó a las familias un cuestionario sobre la higiene bucal y de manos, extraído de Ballesteros (2016): "¿Qué le ba contado su hijo/ a sobre el tema de los microbios? (P1)"; "¿Ha observado algún cambio en el hábito de lavado de dientes (P3) y de manos (P5) de su bijo/ a?".

Tabla 2. Ítems analizados del cuestionario sobre microorganismos y hábitos de higiene (basado en HICORIN -Moreno 2015-).

\begin{tabular}{|l|c|}
\hline \multicolumn{1}{|c|}{ Pregunta $(\mathrm{P})$} & Tipo de respuesta \\
\hline P1: ¿Hay microbios en nuestro entorno? & $\mathrm{M}(\mathrm{D}+\mathrm{A})$ \\
\hline P2: ¿Dónde crees que hay más microbios? & $\mathrm{M}(\mathrm{P}+\mathrm{A})$ \\
\hline P3: ¿Crees que hay microbios en nuestro cuerpo? & $\mathrm{D}$ \\
\hline P4: ¿Cuándo tenemos más microbios en las manos? & $\mathrm{D}$ \\
\hline P5: ¿Cuántas veces te lavaste las manos ayer? & $\mathrm{P}$ \\
\hline P6: ¿Te lavas las manos antes de cada comida? & $\mathrm{P}$ \\
\hline P7: ¿Te lavas las manos después de hacer caca? & $\mathrm{P}$ \\
\hline P8: ¿Te lavas las manos después de hacer pis? & $\mathrm{P}$ \\
\hline P9: ¿Usas jabón cuando te lavas las manos? & $\mathrm{P}$ \\
\hline P10: ¿Alguien te ayuda a lavarte las manos? & $\mathrm{M}(\mathrm{P}+\mathrm{A})$ \\
\hline P11: ¿Te puedes poner malo por no lavarte las manos? & $\mathrm{M}(\mathrm{D}+\mathrm{A})$ \\
\hline P12: ¿Cuándo tenemos más microbios en nuestros dientes? & $\mathrm{D}$ \\
\hline P13: ¿Cuántas veces te lavaste los dientes ayer? & $\mathrm{P}$ \\
\hline P15: ¿Lavarse los dientes ayuda a que no se te piquen? & $\mathrm{D}$ \\
\hline $\begin{array}{l}\text { P16: ¿Desaparecen todos los microbios cuando nos lavamos las } \\
\text { manos/dientes? }\end{array}$ & $\mathrm{D}$ \\
\hline P17: ¿Alguien te ayuda a lavarte los dientes? & $\mathrm{M}(\mathrm{P}+\mathrm{A})$ \\
\hline P19: ¿Hay microbios perjudiciales y beneficiosos? & $\mathrm{D}$ \\
\hline P21: ¿Qué hacen los microorganismos perjudiciales? & $\mathrm{A}$ \\
\hline P22: ¿Para qué se usan los microorganismos beneficiosos? & $\mathrm{A}$ \\
\hline
\end{tabular}

Nota: M: Mixta; D: Dicotómica; A: Abierta; P: Politómica. 


\section{Procedimiento}

En ambos grupos se realizaron nueve sesiones de 45 minutos, incluyendo las tres evaluaciones, a lo largo de las dos últimas semanas de marzo.

\section{Intervención}

- Fase 1a: grupo experimental (dos sesiones).

Elaboración de masa de pan (Figura 1). Además de para iniciar el tema y motivar, la actividad pretendía que el alumno aprendiera que la levadura es un microorganismo que se utiliza en la fabricación de un alimento cotidiano, dando sentido al aprendizaje (Rivero et al. 2017). Preparadas las cantidades exactas de cada ingrediente para que fermentase adecuadamente, la clase fue dividida en dos bloques, uno de ellos utilizó únicamente harina y agua, y el otro adicionó, además, levadura. Se explicaron los pasos a seguir y las masas se colocaron en un rincón del aula. Pasada una hora, en la segunda sesión de esta fase, los alumnos observaron el resultado y se plantearon, sucesivamente, las siguientes cuestiones: “¿Están igual ambas masas? ¿Por qué unos han aumentado y otros no? Figura 1. Alumnos elaborando masa ¿Qué diferencia hay entre ambas preparaciones? ¿Por qué de pan.

los que no tenían levadura no han aumentado? ¿Qué es la levadura? ¿Qué ha hecho la levadura para que crezca el pan?”

- Fase 1b: grupo control (dos sesiones).

Se pidió a los alumnos, por parejas, que escribieran 10 palabras relacionadas con los microorganismos. Seguidamente, se explicó cómo se hacía el pan y la función de la levadura, introduciendo el término microorganismo. También se proyectó un vídeo sobre la fabricación del pan, y escribieron de nuevo 10 palabras que hubieran aprendido. Al día siguiente se repasaron los aspectos trabajados.

- Fase 2: grupo experimental y control (una sesión).

La actividad pretendía enseñar la manera correcta de lavarse manos y dientes. Para las manos se diseñó un vídeo donde se explicaba paso a paso cómo lavárselas correctamente, y los alumnos debían seguir sus indicaciones. En cuanto al cepillado de dientes, el profesor lo mostró haciéndolo él mismo. En el grupo experimental, además, practicaron usando su propio cepillo dental.

- Fase 3a: grupo experimental (una sesión).

Para que los alumnos observasen colonias de microorganismos y la importancia de la higiene, sobre placas Petri (con agar para crecimiento de microorganismos mesófilos) imprimieron sus dedos antes y después del lavado de manos. También se extrajo sarro-saliva de los dientes, con bastoncillos estériles, antes y después del cepillado (Figura 2). En algunos casos, también cultivaron su huella tras introducir un dedo en su nariz.

Las placas se sellaron con cinta adhesiva por motivos de bioseguridad y se animó a los alumnos a comentar, en grupos, sus hipótesis sobre qué sucedería. Las placas se colocaron en un rincón del aula para que los alumnos hicieran un seguimiento, marcando los cambios y rodeando la evolución de las colonias con rotulador. 

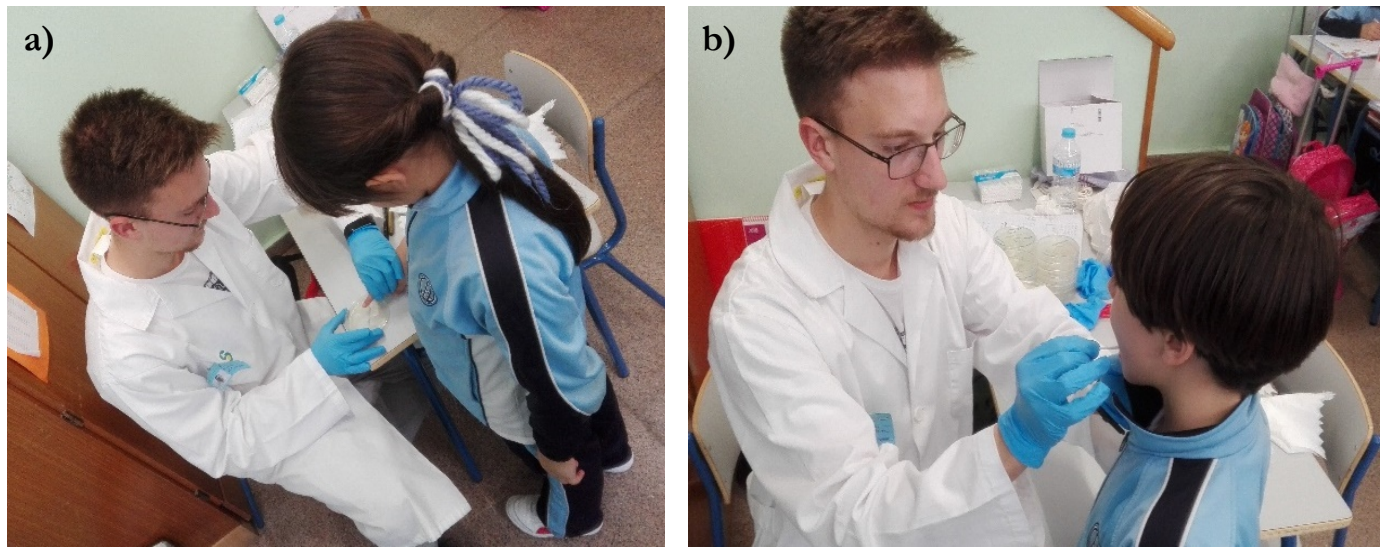

Figura 2. a) Toma de muestra de las manos; b) extracción de muestra bucal.

Pasada una semana, se realizó una sesión para revisar y comentar los resultados. Se compararon las placas con las diferentes condiciones experimentales (Figura 3). Todo el proceso fue guiado y se hicieron preguntas como:

- Si los microorganismos no se pueden ver a simple vista, ¿por qué en las placas sí podemos verlos?

- ¿Por qué hay microorganismos en las placas de "manos y dientes limpios"?

- ¿Hay la misma cantidad en placas de limpios y sucios?

- ¿Han desaparecido todos los microorganismos después de habernos lavado las manos y los dientes?
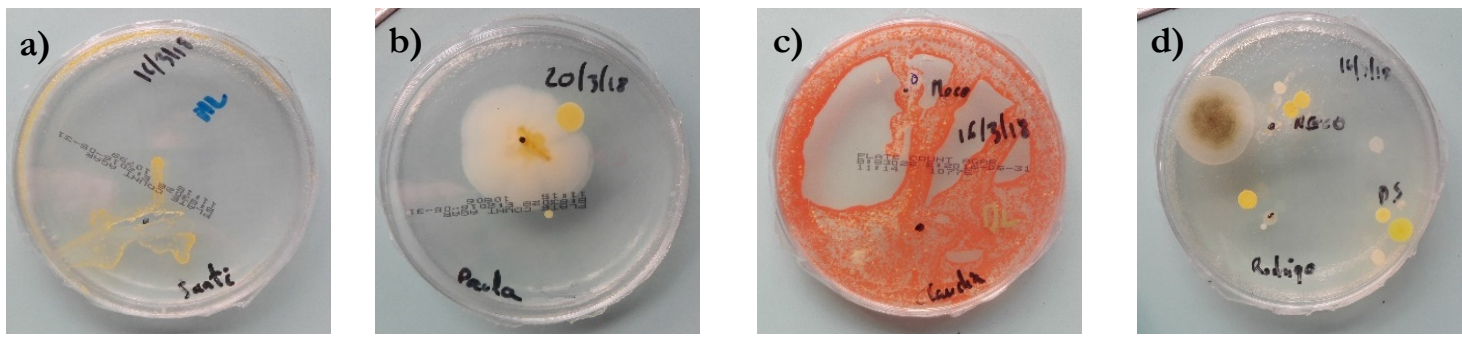

Figura 3. a) Placas "Manos limpias"; b) "manos sucias"; c) "dientes limpios"; d) "dientes sucios".

- Fase 3b: grupo control (una sesión).

En el grupo control se explicó qué eran las placas Petri, en un vídeo observaron la manera de utilizarlas y se visualizaron imágenes de distintos tipos de microorganismos. La práctica totalidad de la sesión se redujo a explicación del profesor.

- Fase 4: grupo experimental y control (dos sesiones).

Se concluyó con una explicación del docente (apoyada en imágenes) sobre los microorganismos, sus tipos, ubicación y funciones, tanto perjudiciales como beneficiosos. En parejas, realizaron una ficha de refuerzo, con cuatro preguntas abiertas, una de opción múltiple, otra de completar con palabras clave, y una última de relacionar imágenes de microorganismos con su nombre. Al día siguiente, se realizó una sesión de repaso sobre las respuestas de esta ficha.

\section{Revisión de libros de texto}

Para averiguar la información que los libros ofrecen sobre los microorganismos y evaluar su posible contribución a la visión que los niños tienen de ellos, se revisaron 10 textos de Ciencias de la Naturaleza de 5 editoriales comunes, de $1^{\text {er }}$ y $2^{\circ}$ curso: Camacho y Rodríguez (2015); Camacho, Luna, Collantes y Rodríguez (2014); Cid et al. (2014); Díaz, Ferri, Hidalgo, 
Marsá y Pérez (2014); Díaz, Ferri, Hidalgo, Marsá y Pérez (2015); Garín, Hidalgo y Moratalla (2015); Gonzalo y Mancheño (2014); Gonzalo, Blanco y Mancheño (2015); Grupo Edebé (2015); Grupo Edebé (2014). Se leyeron todos sus capítulos buscando referencias a microorganismo, microbio o alguno de los seres vivos que incluyen (también virus).

\section{Tiempo de preparación del docente}

Para averiguar y contrastar el tiempo empleado por el docente en la preparación de las diferentes intervenciones, se anotó sistemáticamente la hora de inicio y fin de preparación de las diferentes actividades.

\section{Análisis de datos}

Los datos tienen carácter no paramétrico, dado que aparecen respuestas ordinales y dicotómicas (acierto o error). Las cualitativas se han agrupado y cuantificado por coincidencias y se han aplicado los estadísticos de contraste correspondientes:

Intergrupo (grupo control vs experimental):

- Ítems dicotómicos: tablas de contingencia y $\chi^{2}$ (ji-cuadrado) para comparar entre cuestiones. En caso de vulnerar que más del $25 \%$ de las casillas tenga recuento inferior a 5 , se utilizará el $p$-valor de la prueba exacta de Fisher.

- Ítems politómicos: prueba $U$ de Mann-Withney en ordinales y $\chi^{2}$ en cualitativos.

Intragrupo con medidas repetidas: para apreciar los cambios entre las tres evaluaciones, dentro de cada grupo:

- Ítems dicotómicos: $Q$ de Cochran con post-hoc mediante la prueba de McNemar.

- Ítems politómicos: test de Friedman con post-hoc mediante la prueba de Wilcoxon.

Se consideró que aparecían diferencias estadísticamente significativas cuando $p<0.05$. En los post-hoc se utilizó la corrección de Bonferroni para 3 evaluaciones: $p<0.017$. Para valorar cuál es la magnitud de los cambios se calculó el tamaño de efecto $r$ de Rosenthal y el Odds ratio (en el caso de valores dicotómicos).

\section{Resultados}

\section{Hábitos e ideas previas a la intervención}

\section{Cuestionarios}

Más de la mitad de los alumnos tienen una frecuencia alta de lavado de manos y dientes (Tabla 3). Además, el 61.68\% considera que no lavarse las manos puede ser causa de enfermedad.

Tabla 3. Frecuencia (número de sujetos y, entre paréntesis, su proporción) de lavado de manos (pregunta 5) y dientes (pregunta 13) en los participantes antes de la intervención.

\begin{tabular}{|l|c|c|c|c|c|}
\hline & Nunca & 1 vez & 2 veces & 3 veces & Más de tres veces \\
\hline P5 & $7(6.54)$ & $17(15.88)$ & $15(14.01)$ & $22(20.56)$ & $46(42.99)$ \\
\hline P13 & $5(4.67)$ & $23(21.49)$ & $25(23.36)$ & & $53(49.53)$ \\
\hline
\end{tabular}

En cuanto a los microorganismos, el 50.46\% de los alumnos considera su presencia en nuestro entorno, y un tercio indica que también se encuentran dentro de nuestro cuerpo. Los lugares más frecuentes se recogen en la figura 4. 


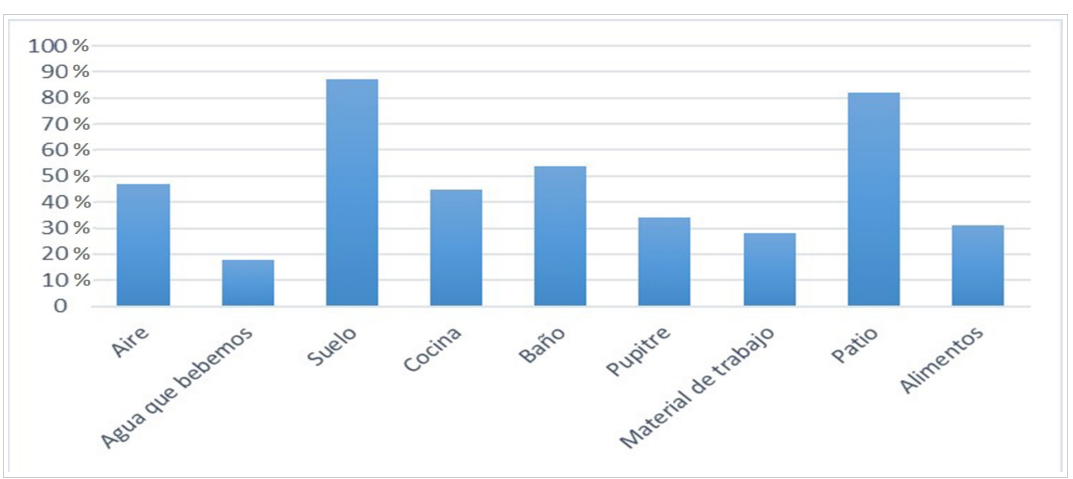

Figura 4. ¿Dónde crees que hay microbios? (P2)

La tabla 4 resume las respuestas a la pregunta 21. En "otros" se incluyen respuestas variadas como: "escaparse", "dan electricidad" o "se mueven". La tabla 5 sintetiza las respuestas a la pregunta 22 (función de los microorganismos).

\section{Dibujos}

La tabla 6 agrupa los resultados del análisis de los dibujos y la figura 5 muestra algunos ejemplos. Casi un tercio les da forma abstracta y, de ellos, el 17.64\% incluye rasgos faciales. Le sigue la forma animal, en su mayoría insectos: piojos, escarabajos, etc. En la forma de bacteria, cinco alumnos le añaden cara a su dibujo. En la categoría "otros" se incluyen formas que no pueden agruparse en las anteriores, como un micrófono, al considerar el niño que esta palabra se parece a microorganismo. Destacamos, por singular, el dibujo antropomorfo de un niño de 7 años, con un cuchillo en la mano y que responde, a la pregunta abierta, que los microorganismos son: "gente fea, mala, tonta, negra, gitana, gente que pega a su enemigo".

Tabla 4. Función que los participantes otorgan a los microorganismos perjudiciales (pretest).

\begin{tabular}{|l|c|c|}
\hline Categoría & $n$ & $\%$ \\
\hline Ponernos malos o causar enfermedades & 53 & 58.24 \\
\hline Hacer daño & 11 & 12.08 \\
\hline Picar los dientes & 5 & 5.49 \\
\hline Causar la muerte & 4 & 4.39 \\
\hline Hacer cosas malas & 3 & 3.29 \\
\hline Otros & 15 & 16.48 \\
\hline Total & 91 & 100.00 \\
\hline
\end{tabular}

n: número de respuestas.

Tabla 5. Función que los participantes otorgan a los microorganismos beneficiosos, en el pretest.

\begin{tabular}{|l|c|c|}
\hline Categoría & $n$ & $\%$ \\
\hline Curar o ayudar & 30 & 54.54 \\
\hline Para analizarlos o estudiarlos & 5 & 9.09 \\
\hline Proteger o ayudar al cuerpo & 4 & 7.27 \\
\hline Vitaminas & 3 & 5.45 \\
\hline Alimentos & 1 & 1.81 \\
\hline Hacer medicinas & 1 & 1.81 \\
\hline Otros & 11 & 20.00 \\
\hline Total & 55 & 100.00 \\
\hline
\end{tabular}

n: número de respuestas. 
Tabla 6. Forma de los microorganismos según los dibujos del alumnado (pretest).

\begin{tabular}{|l|c|c|}
\hline Categoría & $n$ & $\%$ \\
\hline Forma abstracta (Fig. 5b) & 34 & 31.19 \\
\hline Forma animal & 32 & 29.35 \\
\hline Antropomorfo & 13 & 11.92 \\
\hline Forma de bacteria (Fig. 5c) & 8 & 7.33 \\
\hline Forma de extraterrestre (Fig. 5a) & 3 & 2.75 \\
\hline No incluyen dibujo & 12 & 11.00 \\
\hline Otros & 7 & 6.42 \\
\hline Total & 109 & 100.00 \\
\hline
\end{tabular}

$n$ : número de dibujos; \%: proporción sobre el total de dibujos.

El lugar más común donde los alumnos los representan es en el cuerpo humano (28.97\%): el $67.74 \%$ lo hace en la superficie, principalmente en manos y pelo. El $20.56 \%$ los dibujan en el campo.

a)

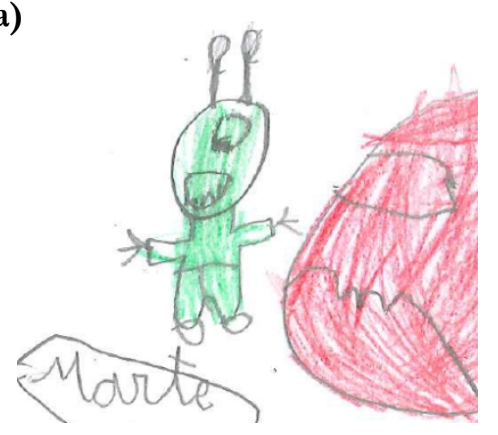

b)

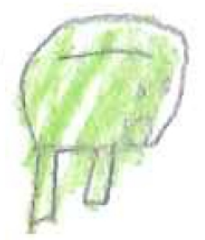

c)

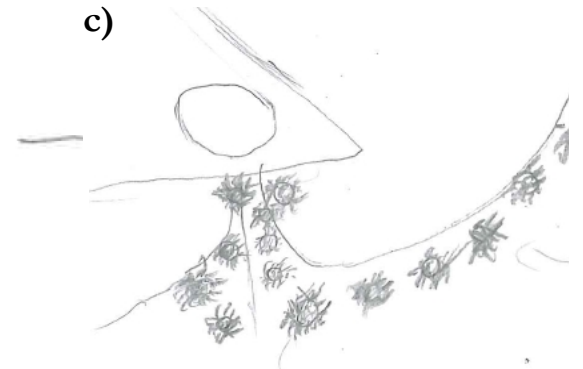

Figura 5. a) Dibujo forma "extraterrestre", 6 años; b) forma "abstracta con cara", 6 años; c) forma "bacteria", 7 años.

Es relevante que, a pesar de disponer de lápices de colores, solo la mitad de los participantes los colorean (49.47\%), cobrando particular relevancia los tonos oscuros de verde, azul, rojo, y el negro (Figura 6).

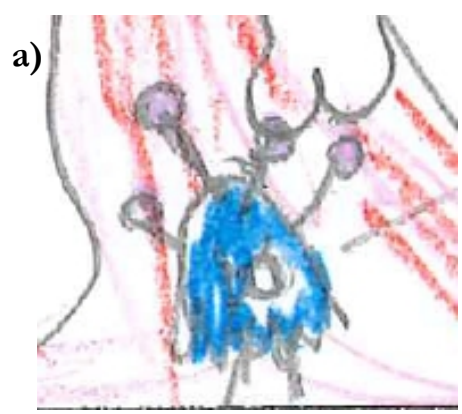

b)

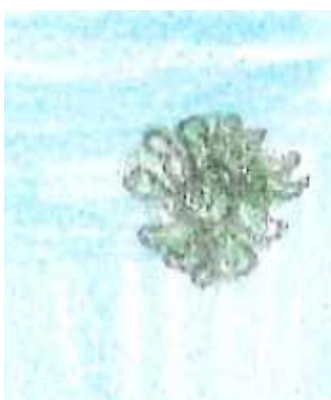

Figura 6. a) Dibujo coloreado en azul, 7 años, grupo control; b) dibujo coloreado en verde, 8 años, grupo experimental

Para averiguar el origen de sus conocimientos iniciales se les preguntó dónde habían oído hablar de los microbios. Solo un $9.34 \%$ citó dos fuentes distintas. Las principales: colegio (28.03\%), entorno familiar (28.03\%), el médico (12.14\%), y medios de comunicación $(8.41 \%)$ -televisión, publicidad y las noticias-.

\section{Resultados tras la intervención}

Las pruebas de contraste entre el grupo control y experimental, para comprobar que ambos parten del mismo nivel de conocimiento y hábitos, se recogen en las tablas 7 y 8 . Solo en las 
cuestiones 9 y 10 aparece una diferencia estadística, de poco tamaño de efecto, en favor del grupo experimental, por lo que ambos son comparables.

Tabla 7. Prueba $\chi^{2}$ entre el grupo control y experimental, para cuestiones dicotómicas (pretest).

\begin{tabular}{|l|l|l|l|l|l|l|l|l|}
\hline & P1 & P3 & P4 & P11 & P12 & P15 & P16 & P19 \\
\hline$\chi^{2}$ & $2.196^{\text {ns }}$ & $0.043^{\text {ns }}$ & $0.163^{\text {ns }}$ & $0.000^{\text {ns }}$ & $0.039^{\text {ns }}$ & $0.710^{\text {ns }}$ & $0.008^{\text {ns }}$ & $0.895^{\text {ns }}$ \\
\hline
\end{tabular}

ns: no significativo.

Tabla 8. Prueba de contraste $U$, entre el grupo control y experimental (cuestiones politómicas, pretest).

\begin{tabular}{|c|c|c|c|c|c|c|c|c|c|c|c|c|c|c|c|c|c|c|}
\hline & \multicolumn{2}{|c|}{ P2 } & \multicolumn{2}{|c|}{ P5 } & \multicolumn{2}{|c|}{ P6 } & \multicolumn{2}{|c|}{ P7 } & \multicolumn{2}{|c|}{ P8 } & \multicolumn{2}{|c|}{ P9 } & \multicolumn{2}{|c|}{ P10 } & \multicolumn{2}{|c|}{ P13 } & \multicolumn{2}{|c|}{ P17 } \\
\hline & Ctr & Exp & Ctr & Exp & Ctr & Exp & Ctr & Exp & Ctr & Exp & Ctr & Exp & Ctr & Exp & Ctr & Exp & Ctr & Exp \\
\hline$n$ & 49 & 53 & 52 & 55 & 51 & 55 & 52 & 55 & 52 & 54 & 52 & 54 & 52 & 55 & 51 & 55 & 49 & 55 \\
\hline $\bar{X}$ & 4.18 & 4.17 & 3.98 & 3.58 & 1.67 & 1.53 & 1.86 & 1.76 & 1.9 & 2 & 1.21 & 1.1 & 1.04 & 1.16 & 2.31 & 2.44 & 1.12 & 1.15 \\
\hline$s$ & 1.83 & 2.33 & 1.21 & 1.41 & 0.77 & 0.58 & 1.01 & 1.15 & 1.11 & 1.25 & 0.46 & 0.45 & 0.19 & 0.37 & 0.84 & 0.92 & 0.33 & 0.36 \\
\hline$U$ & \multicolumn{2}{|c|}{$1261.5^{\mathrm{ns}}$} & \multicolumn{2}{|c|}{$1210.0^{\mathrm{ns}}$} & \multicolumn{2}{|c|}{$1212.5^{\mathrm{ns}}$} & \multicolumn{2}{|c|}{$1292.5^{\mathrm{ns}}$} & \multicolumn{2}{|c|}{$1375.0^{\mathrm{ns}}$} & \multicolumn{2}{|c|}{$1216.0^{*}$} & \multicolumn{2}{|c|}{$1251.0^{*}$} & \multicolumn{2}{|c|}{$1314.0^{\text {ns }}$} & \multicolumn{2}{|c|}{$1316.5^{\mathrm{ns}}$} \\
\hline$Z$ & \multicolumn{2}{|c|}{-0.251} & \multicolumn{2}{|c|}{-1.442} & \multicolumn{2}{|c|}{-1.351} & \multicolumn{2}{|c|}{-0.956} & \multicolumn{2}{|c|}{-0.200} & \multicolumn{2}{|c|}{-2.089} & \multicolumn{2}{|c|}{-2.121} & \multicolumn{2}{|c|}{-0.606} & \multicolumn{2}{|c|}{-0.341} \\
\hline$r$ & & & & & & & & & & & -0 & & & & & & & \\
\hline
\end{tabular}

$n$ : número de individuos; $\bar{X}$ : media; s: desviación típica; $U$ : estadístico de Mann-Withney; $Z$ : aproximación a la normal; $r$ : tamaño del efecto; ns: no significativo; ${ }^{*} p<0.05$.

\section{Variación del aprendizaje intragrupo}

- Grupo control.

En las preguntas dicotómicas (Tabla 9), la prueba $Q$ de Cochran para medidas repetidas, y sus correspondientes pruebas post-hoc (prueba de McNemar), encuentran mejores resultados estadísticos en 4 preguntas (1, 3, 16 y 19). Además, se observa que el conocimiento se mantiene en el tiempo (entre el primer y el segundo postest). La cuestión 1 es la que tiene mejores resultados entre el pre y el segundo postest. En las preguntas ordinales (Tabla 10), la prueba de Friedman encuentra diferencias estadísticas solo en la cuestión 2. Realizando el posthoc con el test de Wilcoxon, nuevamente se observa que las diferencias están entre el pretest y el postest inmediato tras la experiencia $\left(Z_{P_{\mathrm{r}-\mathrm{P} s} 1}=-5.7, p<.001, r=-0.82\right)$ y entre el pretest y el segundo postest $\left(Z_{\mathrm{Pr} P \mathrm{P} 2_{2}}=-5.4, p<.001, r=-.77\right)$, pero esta mejora no se reduce entre ambos postest $\left(Z_{P_{\mathrm{s} 1}-\mathrm{P} \mathrm{P} 2}=-0.2, p>.05\right)$.

Tabla 9. Prueba de contraste entre las tres pruebas realizadas por grupo control (cuestiones dicotómicas).

\begin{tabular}{|c|c|c|c|c|c|c|c|c|c|c|c|c|c|c|c|c|c|c|c|c|c|c|c|c|}
\hline & \multicolumn{3}{|c|}{ P1 } & \multicolumn{3}{|c|}{ P3 } & \multicolumn{3}{|c|}{ P4 } & \multicolumn{3}{|c|}{ P11 } & \multicolumn{3}{|c|}{ P12 } & \multicolumn{3}{|c|}{ P15 } & \multicolumn{3}{|c|}{ P16 } & \multicolumn{3}{|c|}{ P19 } \\
\hline & $\operatorname{Pr}$ & Ps1 & Ps2 & $\operatorname{Pr}$ & Ps1 & Ps2 & $\operatorname{Pr}$ & Ps1 & Ps2 & $\operatorname{Pr}$ & Ps1 & Ps2 & $\operatorname{Pr}$ & Ps1 & Ps2 & $\operatorname{Pr}$ & Ps1 & Ps2 & $\operatorname{Pr}$ & Ps1 & Ps2 & $\operatorname{Pr}$ & Ps1 & Ps2 \\
\hline$A$ & 27 & 54 & 54 & 16 & 41 & 42 & 47 & 41 & 42 & 35 & 32 & 34 & 37 & 39 & 46 & 42 & 45 & 48 & 10 & 10 & 21 & 34 & 55 & 55 \\
\hline$N$ & \multicolumn{3}{|c|}{57} & \multicolumn{3}{|c|}{57} & \multicolumn{3}{|c|}{57} & \multicolumn{3}{|c|}{57} & \multicolumn{3}{|c|}{57} & \multicolumn{3}{|c|}{57} & \multicolumn{3}{|c|}{57} & \multicolumn{3}{|c|}{57} \\
\hline$Q$ & \multicolumn{3}{|c|}{$45.56^{* * *}$} & \multicolumn{3}{|c|}{$36.17^{* * *}$} & \multicolumn{3}{|c|}{$2.48^{\mathrm{ns}}$} & \multicolumn{3}{|c|}{$0.64^{\mathrm{ns}}$} & \multicolumn{3}{|c|}{$5.15^{\mathrm{ns}}$} & \multicolumn{3}{|c|}{$2.7^{\mathrm{ns}}$} & \multicolumn{3}{|c|}{$9.31^{* * *}$} & \multicolumn{3}{|c|}{$36.75^{* * *}$} \\
\hline \multicolumn{3}{|c|}{$O R_{\mathrm{Pr}-\mathrm{Ps} 1}$} & $14.5^{\text {*** }}$ & \multicolumn{3}{|c|}{$7.2^{* * *}$} & & & & & & & & & & & & & \multicolumn{3}{|c|}{$10.5^{\text {*** }}$} & \multicolumn{3}{|c|}{$22.0^{* * *}$} \\
\hline \multicolumn{3}{|c|}{$O R_{\text {Pr-Ps } 2}$} & $28.0^{* * *}$ & \multicolumn{3}{|c|}{$14.0^{* * *}$} & & & & & & & & & & & & & \multicolumn{3}{|c|}{$3.8^{* *}$} & & $2.0^{*}$ & \\
\hline & ${ }_{\mathrm{Ps} 1-\mathrm{Ps}}$ & & ns & & ns & & & & & & & & & & & & & & & ns & & & $\mathrm{ns}$ & \\
\hline
\end{tabular}

Pr: evaluación previa; Ps1: postest 1 (inmediato tras la experiencia); Ps2: postest 2 (dos meses después de la experiencia); A: número de aciertos; $N$ : número de individuos participantes; $Q$ : estadístico de Cochran; OR: Odds ratio para la prueba de McNemar; ns: no significativo; ${ }^{* *} p<0.01 ; * * * p<0.001$. 
Tabla 10. Estadísticos de contraste entre las tres pruebas del grupo control (cuestiones politómicas).

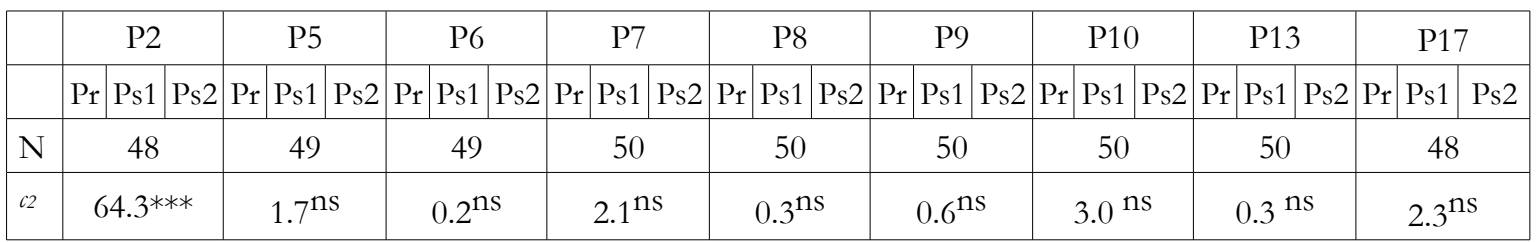

Pr: evaluación previa; Ps1: postest 1 (inmediato tras la experiencia); Ps2: postest 2 (dos meses después de la experiencia); $c^{2}$ : valor $j i$-cuadrado para prueba de Friedman; $N$ : número de individuos participantes.

\section{- Grupo experimental.}

Los resultados de las preguntas dicotómicas (Tabla 11) coinciden con los del grupo control, aumentando en la cuestión 16, en la misma línea (mejor resultado en ambas posevaluaciones).

En el caso de las de tipo politómico, igualmente coincide en que solo mejora estadísticamente la pregunta 2 , tanto en el postest inmediato $\left(Z_{\text {Pr-Ps1 }}=-4.8, p<.001, r=-.68\right)$, como en el realizado dos meses después ( $\left.\mathrm{Z}_{\mathrm{Pr}-\mathrm{P}_{\mathrm{s}}}=-5.4, p<.001, r=-.76\right)$. Curiosamente, el contraste de ambas evaluaciones posteriores a la intervención indica que los resultados son incluso mejores dos meses después de la finalizarla $\left(\mathrm{Z}_{\mathrm{Ps} 1 \mathrm{Ps} 2}=-2.6, p<.01, r=-.37\right)$.

Tabla 11. Prueba de contraste entre las tres pruebas realizadas por el grupo experimental (cuestiones dicotómicas)

\begin{tabular}{|c|c|c|c|c|c|c|c|c|c|c|c|c|c|c|c|c|c|c|c|c|c|c|c|c|}
\hline & \multicolumn{3}{|c|}{ P1 } & \multicolumn{3}{|c|}{ P3 } & \multicolumn{3}{|c|}{ P4 } & \multicolumn{3}{|c|}{ P11 } & \multicolumn{3}{|c|}{ P12 } & \multicolumn{3}{|c|}{ P15 } & \multicolumn{3}{|c|}{ P16 } & \multicolumn{3}{|c|}{ P19 } \\
\hline & $\operatorname{Pr}$ & Ps1 & Ps2 & $\operatorname{Pr}$ & Ps1 & Ps2 & $\operatorname{Pr}$ & Ps1 & Ps2 & $\operatorname{Pr}$ & Ps1 & Ps2 & $\operatorname{Pr}$ & Ps1 & Ps2 & $\operatorname{Pr}$ & Ps1 & Ps2 & $\operatorname{Pr}$ & Ps1 & Ps2 & $\operatorname{Pr}$ & Ps1 & Ps2 \\
\hline A & 27 & 49 & 53 & 19 & 36 & 40 & 49 & 50 & 48 & 31 & 35 & 39 & 38 & 32 & 33 & 46 & 45 & 46 & 12 & 31 & 29 & 34 & 53 & 55 \\
\hline$N$ & \multicolumn{3}{|c|}{57} & \multicolumn{3}{|c|}{57} & \multicolumn{3}{|c|}{57} & \multicolumn{3}{|c|}{57} & \multicolumn{3}{|c|}{57} & \multicolumn{3}{|c|}{57} & \multicolumn{3}{|c|}{57} & \multicolumn{3}{|c|}{57} \\
\hline$Q$ & \multicolumn{3}{|c|}{$39.2^{* * *}$} & \multicolumn{3}{|c|}{$28.7^{* * *}$} & \multicolumn{3}{|c|}{$0.38^{\mathrm{ns}}$} & \multicolumn{3}{|c|}{$4.0^{\mathrm{ns}}$} & \multicolumn{3}{|c|}{$2.58^{\mathrm{ns}}$} & \multicolumn{3}{|c|}{$0.14^{\mathrm{ns}}$} & \multicolumn{3}{|c|}{$21.1^{* * *}$} & \multicolumn{3}{|c|}{$34.35^{* * *}$} \\
\hline \multicolumn{3}{|c|}{$O R_{\text {Pr-Ps1 }}$} & $29.0^{* * *}$ & \multicolumn{3}{|c|}{$18.0^{* * *}$} & & & & & & & & & & & & & \multicolumn{3}{|c|}{$10.5^{\mathrm{ns}}$} & \multicolumn{3}{|c|}{$20.0^{* * *}$} \\
\hline \multicolumn{3}{|c|}{$O R_{\text {Pr-Ps2 }}$} & $27.0^{* * *}$ & \multicolumn{3}{|c|}{$22.0^{* * *}$} & & & & & & & & & & & & & \multicolumn{3}{|c|}{$3.8^{* *}$} & & \$) $* * *$ & \\
\hline $\mathrm{OK}$ & Ps1-Ps2 & & ns & & $\mathrm{ns}$ & & & & & & & & & & & & & & & ns & & & ns & \\
\hline
\end{tabular}

Pr: evaluación previa; Ps1: postest 1 (inmediato tras la experiencia); Ps2: postest 2 (dos meses después de la experiencia); A: número de aciertos; N: número de individuos participantes; Q: estadístico de Cochran; OR: Odds ratio para la prueba de McNemar; ns: no significativo; $*^{*} p<0.01 ; * * *<0.001$; (\$): OR no calculado por ser una de las casillas de la matriz igual a cero.

Tabla 12. Contraste de respuestas entre las tres pruebas del grupo experimental (cuestiones politómicas).

\begin{tabular}{|c|c|c|c|c|c|c|c|c|c|c|c|c|c|c|c|c|c|c|}
\hline & \multicolumn{3}{|c|}{ P2 } & P5 & \multicolumn{2}{|c|}{ P6 } & \multicolumn{2}{|c|}{ P7 } & \multicolumn{2}{|c|}{ P8 } & \multicolumn{2}{|c|}{ P9 } & \multicolumn{2}{|c|}{ P10 } & \multicolumn{2}{|r|}{ P13 } & \multicolumn{2}{|c|}{ P17 } \\
\hline & $\operatorname{Pr}$ & Ps1 & Ps2 & $\begin{array}{lll}\text { Pr } & \text { Ps1 } & \text { Ps2 }\end{array}$ & Pr Ps1 & Ps2 & Pr Ps1 & Ps2 & $\operatorname{Pr} \mid \operatorname{Ps} 1$ & Ps2 & Pr $\quad$ Ps1 & Ps2 & Pr Ps1 & Ps2 & $\operatorname{Pr} \mathrm{P}$ & \begin{tabular}{l|l} 
Ps1 & Ps 2
\end{tabular} & Pr Ps1 & Ps2 \\
\hline$N$ & & 50 & & 52 & 53 & & 53 & & 52 & & 52 & & 53 & & & 50 & 53 & \\
\hline$\chi^{2}$ & & 48.9* & & $2.7^{\mathrm{ns}}$ & $0.2^{1}$ & & $4.4^{1}$ & & 1.3 & & $3.6^{1}$ & & 2.0 & & & $2.3^{\mathrm{ns}}$ & $2.4^{\mathrm{t}}$ & \\
\hline
\end{tabular}

Pr: evaluación previa; Ps1: postest 1 (inmediato tras la experiencia); Ps2: postest 2 (dos meses después de la experiencia); $\chi^{2}$ : valor $j i$-cuadrado para prueba de Friedman; $N$ : número de individuos participantes; $Z$ : valor del estadístico de Wilcoxon; $r$ : tamaño del efecto; ns: no significativo; ${ }^{* *} p<0.01$; ${ }^{* * *} p<0.001$.

\section{Contraste entre los dos grupos}

- Contraste grupo control - experimental en el postest inmediato.

En relación a las preguntas con respuesta de tipo dicotómico, solo se encuentran diferencias estadísticas en la $15\left(\chi^{2}=12.7 ; p<0,001 ; V=0.472\right)$. La tabla 13 resume las politómicas: solo aparecen diferencias estadísticas en la pregunta 2, donde el número de respuestas es 
ligeramente superior en el grupo control, con tamaño de efecto medio, y en la 10, ligeramente a favor del grupo experimental, pero con un tamaño de efecto muy bajo.

Tabla 13. Contraste de las respuestas entre el grupo control y experimental (propuestas politómicas, postest inmediato)

\begin{tabular}{|c|c|c|c|c|c|c|c|c|c|c|c|c|c|c|c|c|c|c|}
\hline & \multicolumn{2}{|c|}{ P2 } & \multicolumn{2}{|c|}{ P5 } & \multicolumn{2}{|c|}{ P6 } & \multicolumn{2}{|c|}{ P7 } & \multicolumn{2}{|c|}{ P8 } & \multicolumn{2}{|c|}{ P9 } & \multicolumn{2}{|c|}{ P10 } & \multicolumn{2}{|c|}{ P13 } & \multicolumn{2}{|c|}{ P17 } \\
\hline & Ctr & Exp & Ctr & Exp & Ctr & Exp & Ctr & Exp & Ctr & Exp & Ctr & Exp & Ctr & Exp & Ctr & Exp & Ctr & Exp \\
\hline$N$ & 56 & 54 & 55 & 55 & 56 & 55 & 56 & 55 & 56 & 55 & 56 & 55 & 56 & 55 & 56 & 55 & 56 & 55 \\
\hline $\bar{X}$ & 7.39 & 6.1 & 4.18 & 3.8 & 1.57 & 1.58 & 1.71 & 1.96 & 1.88 & 2 & 1.2 & 1.3 & 1 & 1.1 & 2.5 & 2.5 & 1.1 & 1.2 \\
\hline$s$ & 1.77 & 1.98 & 1 & 1.2 & 0.74 & 0.9 & 1 & 1.3 & 1.1 & 1.2 & 0.46 & 0.63 & 0.2 & 0.3 & 0.78 & 0.88 & 0.3 & 0.4 \\
\hline$U$ & \multicolumn{2}{|c|}{$931.0^{* * *}$} & \multicolumn{2}{|c|}{$1268.0^{\mathrm{ns}}$} & \multicolumn{2}{|c|}{$1473.5^{\mathrm{ns}}$} & \multicolumn{2}{|c|}{$1427.5^{\mathrm{ns}}$} & \multicolumn{2}{|c|}{$1437.0^{\text {ns }}$} & \multicolumn{2}{|c|}{$1469.5^{\mathrm{ns}}$} & \multicolumn{2}{|c|}{$1482.5^{*}$} & \multicolumn{2}{|c|}{$1471.0^{\mathrm{ns}}$} & \multicolumn{2}{|c|}{$1425.0^{\mathrm{ns}}$} \\
\hline$Z$ & \multicolumn{2}{|c|}{-3.53} & \multicolumn{2}{|c|}{-1.55} & \multicolumn{2}{|c|}{-0.45} & \multicolumn{2}{|c|}{-0.74} & \multicolumn{2}{|c|}{-0.65} & \multicolumn{2}{|c|}{-0.64} & \multicolumn{2}{|c|}{-0.76} & \multicolumn{2}{|c|}{-0.45} & \multicolumn{2}{|c|}{-1.15} \\
\hline$r$ & \multicolumn{2}{|c|}{-0.34} & & & & & & & & & & & \multicolumn{2}{|c|}{-0.2} & & & & \\
\hline
\end{tabular}

$N$ : número de individuos; $\bar{X}$ : media; $s$ desviación típica; $U$ : estadístico de Mann-Withney; $Z$ : aproximación a la normal; $r$ : tamaño del efecto; ns: no significativo; ${ }^{*} p<0.05 ; * * *<<0.001$.

- Contraste entre el grupo control y el experimental en el postest 2 meses después.

No aparecen diferencias estadísticamente significativas (pruebas $\chi^{2}$ y $U, p>0.05$ ) en ninguna de las cuestiones propuestas.

En cuanto a las preguntas abiertas, la tabla 14 muestra la comparación de los tres momentos observados, en relación a la pregunta 21 sobre las funciones de los microorganismos perjudiciales. El número de respuestas aumenta notablemente en ambos grupos, control y experimental, pero la prueba $\chi^{2}$ indica que no hay diferencias entre ellos en ninguna evaluación. En "otros", algunos alumnos incluyen "las vacunas" como función perjudicial, debido a la molestia que sienten cuando se las inyectan. De modo similar ocurre en relación con las funciones beneficiosas (Tabla 15), aunque en este caso, llama la atención que ambos grupos reducen su número de respuestas en el postest 2 .

Tabla 14. Función que los participantes asignan a los microorganismos perjudiciales, en los tres momentos registrados.

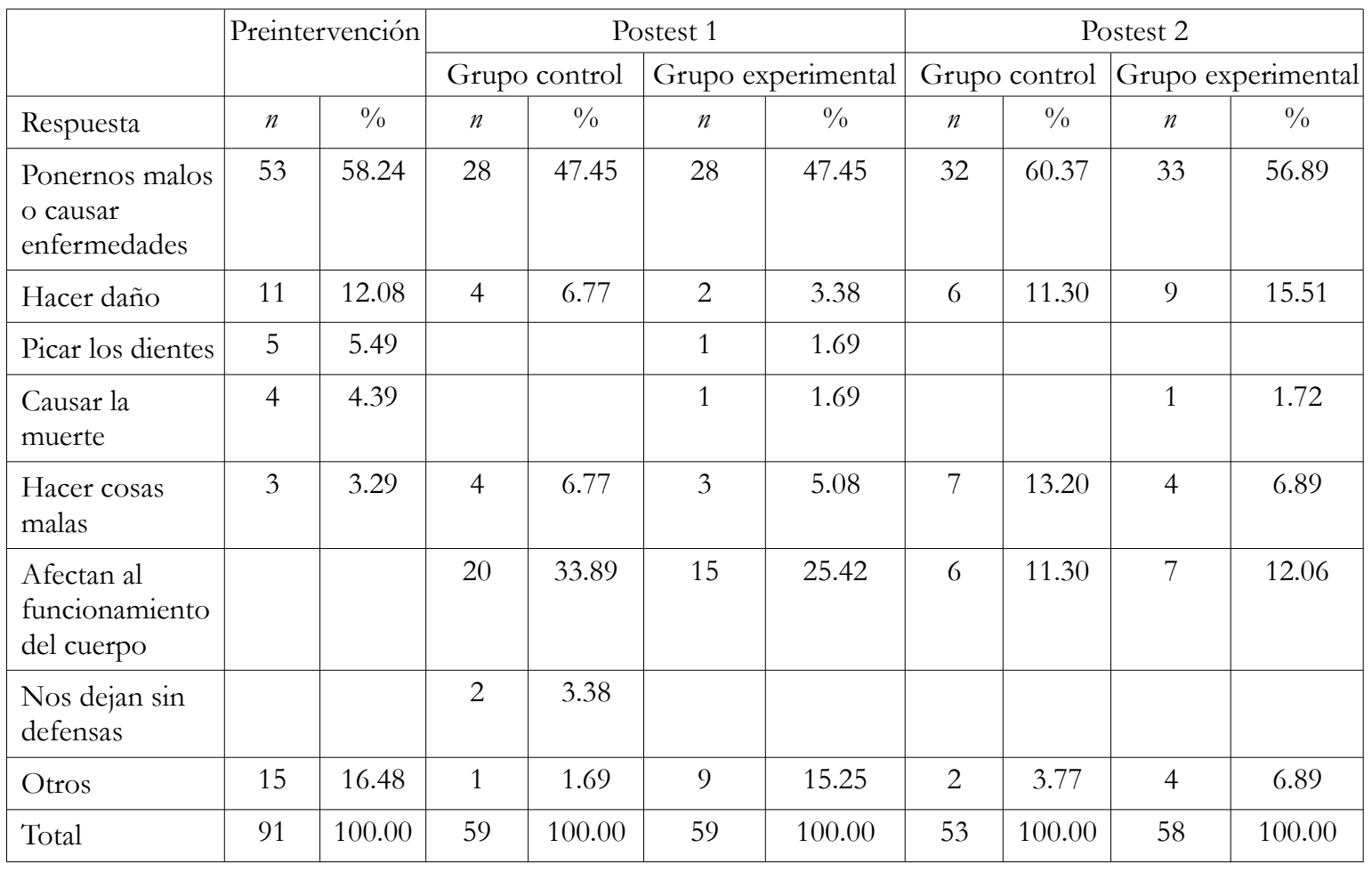

$n$ : número de respuestas; \%: porcentaje sobre el total de respuestas. 
Tabla 15. Función que los participantes otorgan a los microorganismos beneficiosos.

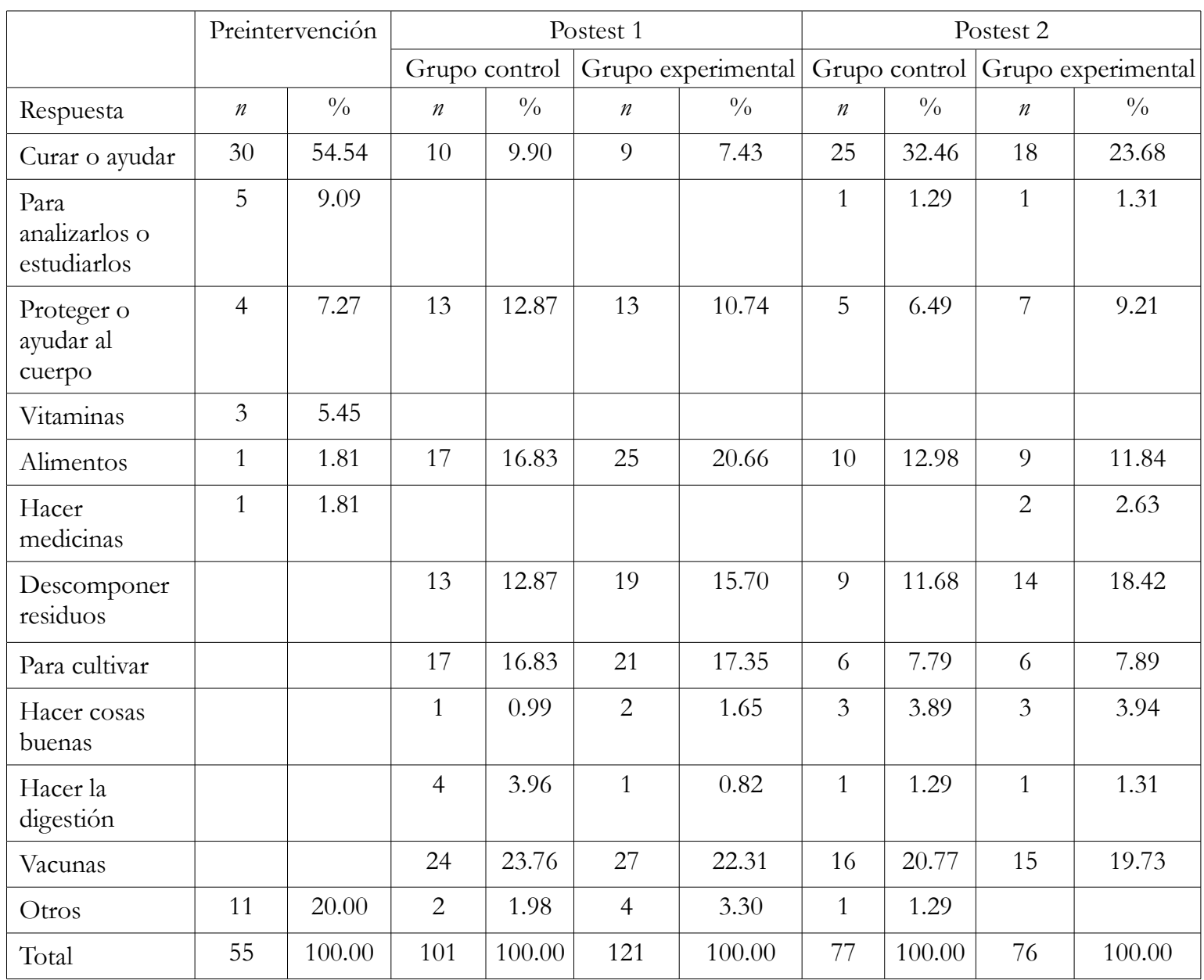

$n$ : número de respuestas; \%: porcentaje sobre el total de respuestas.

\section{Percepción de las familias}

Se recogieron datos de 97 de las 114 familias participantes. Estas han encontrado cambios en los hábitos de higiene de dientes y manos en los niños y, aunque son superiores en el grupo experimental (Figura 7), la prueba de Fisher indica que las diferencias entre grupos no son estadísticamente significativas ( $p>$.05).

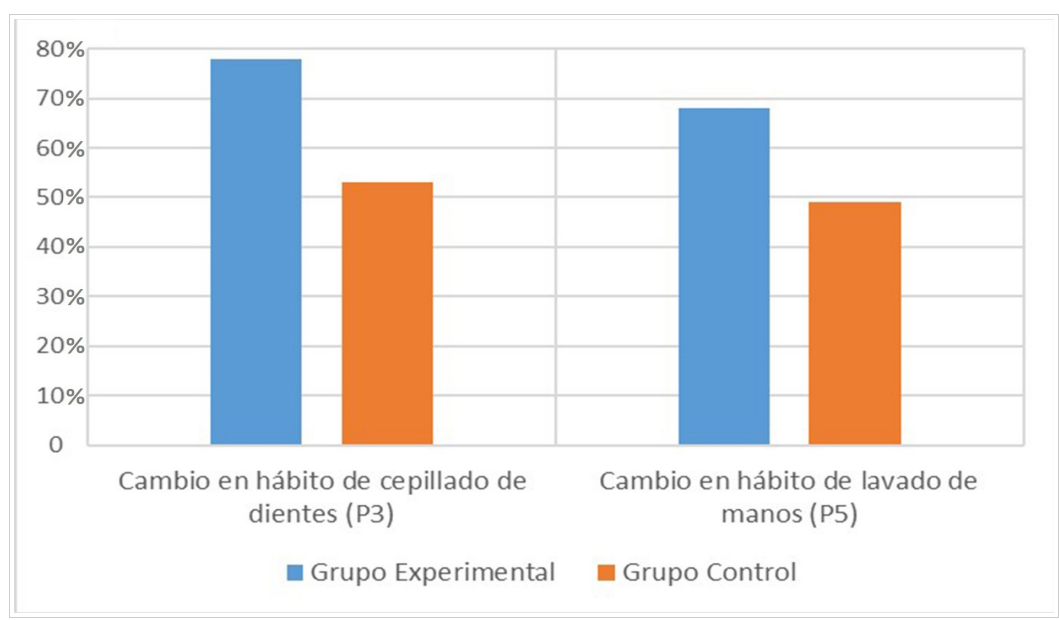

Figura 7. Percepción familiar de cambios en el hábito de los alumnos. 


\section{Tiempo utilizado por el docente}

El tiempo dedicado al diseño y preparación de las sesiones fue:

- Fase 1a: grupo experimental (2 sesiones): 4.5 horas, para la compra de materiales, pruebas realizadas para determinar las cantidades exactas para una fermentación adecuada y la preparación de las unidades individualizadas del material para los niños.

- Fase 1b: grupo control (2 sesiones): 0.5 horas, para búsqueda de vídeos.

- Fase 2 grupo experimental y control (1 sesión en cada): 7 horas, dedicadas a la elaboración del vídeo sobre el lavado de manos.

- Fase 3a: grupo experimental (1 sesión): 5.5 horas, para búsqueda y adquisición de placas Petri y de agar, su preparación y pruebas realizadas.

- Fase 3b: grupo control (1 sesión): 0.5 horas, dirigidas a la búsqueda de vídeos e imágenes.

- Fase 4: grupo experimental y control (2 sesiones en cada): 4 horas, para diseñar la presentación digital y la ficha de repaso.

La intervención teórica acumuló un tiempo de preparación de 12 h, y la experimental, 21 h, un $75 \%$ superior.

\section{Contenido en los libros de texto}

Las únicas referencias encontradas en las editoriales analizadas han sido en el libro de $2^{\circ}$ de Primaria (Díaz et al. 2015): a) se mencionan los microbios dañinos como "causantes de enfermedades"; b) se identifican los microbios y los hongos como "seres vivos que se alimentan de restos de seres y enriquecen el suelo".

\section{Discusión y conclusiones}

En este estudio, el conocimiento de los niños sobre microorganismos es pobre, además de bastante negativo, considerándolos, principalmente, agentes causantes de enfermedades en los seres humanos, lo que coincide con otros autores (Ballesteros et al. 2018, Byrne 2011, Choi y Hong 2014, Deniz y Sahin 2010, Domínguez et al. 2018, Faccio et al. 2013, Ruiz-Gallardo y Paños 2017).

Aporta, además, datos empíricos sobre el origen de esos conocimientos: familia, colegio, médico o televisión. La perspectiva negativa puede tener cierta lógica en la familia, desde donde se trata de evitar los patógenos (higiene). También en el médico, al que con frecuencia se acude por tener una enfermedad infecciosa (aunque también el niño va para ser vacunado, que sería positivo). Los medios de comunicación y la publicidad televisiva contribuyen, así mismo, a esta mala imagen (Deniz y Sahin 2010). Si se observa la publicidad, a excepción de los anuncios de alimentos probióticos, generalmente se centran en su aspecto negativo.

Pero llama la atención que destaquen al colegio. Estudios como el de Ballesteros et al. (2018) encuentran que los libros de texto contribuyen a dar mala imagen. Pero no es el caso de este análisis, en donde tan solo uno de los diez libros ofrece información relativa a los microorganismos. Menciona, además, tanto aspectos negativos (causan enfermedad), como positivos (enriquecen el suelo), por lo que la perspectiva que pueda extraerse es equilibrada. No obstante, este libro no era el usado por los participantes de este estudio. Por tanto, habría que evaluar la percepción de los maestros ya que, posiblemente, su visión sea igualmente negativa y podrían ser la fuente de esta imagen que tienen los niños de los microbios. Ello puede ser motivo de futuros estudios, junto a otras concepciones alternativas, aún presentes en las aulas. 
Los dibujos han proporcionado información valiosa sobre las ideas previas de los niños. Forma: principalmente abstracta, que para Faccio et al. (2013) significa vacío en su conocimiento; de animal pequeño, familiar para el niño, como insectos; de micrófono, por parecerse las palabras; de extraterrestre (Byrne 2011), que interpretamos como algo ajeno a su mundo. Color: usando una gama (morado, verde, negro) que se puede asociar con peligro o con enfermedad (Bedard 2003). Lugar donde aparecen: principalmente, el cuerpo humano (Ballesteros et al. 2018, Faccio et al. 2013) y el campo (Choi y Hong 2014). No obstante, cuando se les pregunta, el suelo y el baño son los lugares que consideran con más microorganismos, en la misma línea que Ballesteros et al. (2018).

Independientemente de la metodología de aprendizaje empleada, los resultados muestran una mejora en el conocimiento en ambos postest, aunque no en los hábitos de higiene que, según los niños, se mantienen. Sin embargo, no hay diferencias de conocimiento y hábitos entre las metodologías empleadas, coincidiendo con otras investigaciones (Ballesteros et al. 2018, RuizGallardo y Paños 2017), aunque contrasta con los resultados de Faccio et al. (2013), cuya intervención produjo mejores resultados en el grupo que había realizado la experiencia práctica.

Explicar por qué no funciona mucho mejor el método experimental que el más transmisivo no es sencillo, ya que parece ir en contra de las tendencias de innovación escolar. No obstante, hay autores que apoyan la instrucción directa, como Kirschner et al. (2006), basándose en que los métodos menos guiados producen mayor carga cognitiva. Estudios posteriores lo corroboran en niños (Matlen y Klahr 2013, Chase y Klahr 2017). Siguiendo a estos autores, la explicación podría ser que la memoria de trabajo se ocupa con las tareas propias de la experimentación, mientras que el aprendizaje del conocimiento pasa a un segundo plano.

Basándonos en las respuestas de las familias, podríamos pensar en una segunda hipótesis: a excepción de una, ninguna de sus respuestas mencionó la elaboración de masa de pan, mientras sí la actividad de placas Petri. Podría entenderse que a las experiencias de aspecto más lúdico (como podría ser la elaboración de masa de pan), los niños le otorguen menor valor cognoscitivo que a otras más científicas, más ortodoxas y académicas, como es la de las placas Petri o la explicación del maestro.

La opinión de las familias ha sido muy importante porque, a pesar de que en los cuestionarios a los niños no se aprecian cambios en los hábitos higiénicos trabajados, los padres observan que han cambiado mucho, pero en la forma en que se produce el lavado de manos y dientes, algo que no ha recogido el cuestionario cerrado, aunque sí una observación externa. Pero al igual que en los conocimientos, a pesar de que las opiniones son más favorables en el grupo experimental, no pueden considerarse estadísticamente diferentes, algo que ya detectaron estudios como Faccio et al. (2013) o Ballesteros et al. (2018).

Finalmente, la preparación e intervención experimental conlleva un $75 \%$ más de tiempo que la tradicional (realizando 3 actividades experimentales), tiempo que se multiplicaría a razón del número de actividades propuesto. Aunque en las siguientes ocasiones que se apliquen estas mismas actividades el tiempo de preparación pueda reducirse sustancialmente, antes de realizar cualquier innovación, motu proprio o por requerimiento curricular, es importante considerar este detalle y que el profesor mida sus fuerzas, ya que suele encontrarse muy sobrecargado debido a la notable labor administrativa a la que se ve sometido.

\section{Referencias}

Ballesteros M. I. (2016) Los microorganismos en el aula: una experiencia a través de la bigiene. Trabajo Fin de Grado inédito. Albacete: Facultad de Educación. 
Ballesteros M., Paños E., Ruiz-Gallardo J. (2018) Los microorganismos en la educación primaria. Ideas de los alumnos de 8 a 11 años e influencia de los libros de texto. Enseñanza de las ciencias, 36(1), 79-98.

Bedard N. (2003) Cómo interpretar los dibujos de los niños. Barcelona: Sirio.

BOE (2014) Real Decreto 126/2014, de 28 de febrero, por el que se establece el currículo básico de la Educación Primaria. Boletín Oficial del Estado, 52, 19349 a 19420

Brooks G., Carroll K., Butel J., Morse S., Mietzner T. (2011) Microbiología Médica (25. ed.). México: McGraw-Hill.

Byrne J. (2011) Models of Micro-organisms: Children's knowledge and understanding of micro-organisms from 7 to 14 years old. International Journal of Science Education, 33(14), 1927-1961.

Camacho V., Rodríguez M. (2015) Ciencias de la Naturaleza. $2^{\circ}$ Primaria. Madrid: Santillana.

Camacho V., Luna S., Collantes C., Rodríguez M. (2014) Ciencias de la Naturaleza. $1^{\circ}$ Primaria. Madrid: Santillana.

Cañal P., García-Carmona A., Cruz-Guzmán M. (2016) Didáctica de las Ciencias Experimentales en Educación Primaria. Madrid: Paraninfo.

Chase C. C., Klahr D. (2017) Invention versus direct instruction: for some content, it'sa tie. Journal of Science Education and Technology, 26(6), 582-596.

Choi Y., Hong S-H. (2014) Elementary Students' Perceptions Concerning Inhabiting Environments of Small Organisms Through Analysis of Drawings and Associated Words. Educación ambiental, 27(3), 330-344.

Cid A., Matias T., Garín M., Hernández E., López S., Martín I., Navarro A. (2014) Ciencias de la Naturaleza. $1^{\circ}$ Primaria. Madrid: SM.

Costa M., López E. (1996) Educación para la salud. Una estrategia para cambiar los estilos de vida. Madrid: Pirámide.

Deniz H., Sahin N. (2010) Primary school students' basic knowledge, opinions and risk perceptions about microorganisms. Procedia Social and Behavioral Sciences, 2, 4398-4401.

Díaz C., Ferri M., Hidalgo O., Marsá M., Pérez E. (2014) Ciencias de la Naturaleza. $1^{\circ}$ Primaria. Aprender es crecer. Madrid: Anaya.

Díaz C., Ferri M., Hidalgo O., Marsá M., Pérez E. (2015) Ciencias de la Naturaleza. $2^{\circ}$ Primaria. Aprender es crecer. Madrid: Anaya.

DOCM (2014). Decreto 54/2014, de 10/07/2017, por el que se establece el currículo de la Educación Primaria en la Comunidad Autónoma de Castilla-La Mancha. Diario Oficial de Castilla-La Mancha, 132, 18498-18909.

Dominguez C., Leporo N., Franco M., Inglez G., Gonçalves V., Bizerra A. (2018) Learning about Microorganisms in Childhood: Four to Six-Year-Old Children's Voice in Kindergartens and Museums. Revista Brasileira de Pesquisa em Educação em Ciências, 18(1), $1-25$.

Faccio E., Costa N., Losasso C., Cappa V., Mantovani C., Cibin V. ... Ricci A. (2013) What programs work to promote health for children? Exploring beliefs on microorganisms and on food safety control behavior in primary schools. Food Control, 33, 320-329.

Frías A. (2002) Salud pública y educación para la salud. Barcelona: Masson. 
Garín M., Hidalgo J., Moratalla V. (2015) Ciencias de la Naturaleza. $2^{\circ}$ Primaria. Madrid: SM.

Gonzalo S., Mancheño R. (2014) Ciencias de la Naturaleza. $1^{\circ}$ Primaria. Zaragoza: Edelvives.

Gonzalo S., Blanco D., Mancheño R. (2015) Ciencias de la Naturaleza. $2^{\circ}$ Primaria. Zaragoza: Edelvives.

Grupo Edebé (2014) Ciencias de la Naturaleza. $1^{\circ}$ Primaria. Barcelona: Edebé.

Grupo Edebé (2015) Ciencias de la Naturaleza. $2^{\circ}$ Primaria. Barcelona: Edebé.

Harvey R., Champe P., Fisher B. (2008) Microbiología. Barcelona: Wolters Kluwer.

Hernández M. (2016) Microbiología de los Alimentos. Fundamentos y Aplicaciones en Ciencias de la Salud. México: Editorial Médica Panamericana.

Higashida B. (2013) Ciencias de la salud (7. a ed.). México: McGraw-Hill.

Jiménez M., Caamaño A., Oñorbe A., Pedrinaci E., Pro A. (2003) Enseñar ciencias. Barcelona: Graó.

Kirschner P. A., Sweller J., Clark R. E. (2006) Why minimal guidance during instruction does not work: An analysis of the failure of constructivist, discovery, problem-based, experiential, and inquiry-based teaching. Educational psychologist, 41(2), 75-86.

Martí J. (2012) Aprender ciencias en la Educación Primaria. Barcelona: Graó.

Matlen B. J., Klahr D. (2013) Sequential effects of high and low instructional guidance on children's acquisition of experimentation skills: Is it all in the timing? Instructional Science, 41, 621-634.

Mora F. (2013) Neuroeducación. Madrid: Alianza Editorial.

Moreno F. (2015) Diseño y validación de un cuestionario para determinar los bábitos y conocimientos en bigiene corporal infantil, y su aplicación en escolares y menores en desamparo de la Región de Murcia. Tesis de Licenciatura. Murcia: Universidad de Murcia.

OMS (1948) Constitución de la Organización Mundial de la Salud. Official Records of the World Health Organization, $\mathrm{N}^{\mathrm{o}} 2$.

Öncü E., Vayısoğlu S. K., Lafci D., Yurtsever D., Bulut E. R., Peker E. (2019) Comparison of interactive education versus fluorescent concretization on hand hygiene compliance among primary school students: A randomized controlled trial. The Journal of School Nursing, 35(5), 337-347.

Pradhan N. A., Mughis,W., Ali T. S., Naseem M., Karmaliani R. (2020) School-based interventions to promote personal and environmental hygiene practices among children in Pakistan: protocol for a mixed methods study. BMC Public Health, 20, 1-14.

Rivero A., Martín R., Solís E., Porlán R. (2017) Didáctica de las ciencias experimentales en educación primaria. Madrid: Síntesis.

Rosa M., Prieto J., Navarro J. (2011) Microbiología en ciencias de la salud: Conceptos y aplicaciones (3. ${ }^{2}$ ed.). Barcelona: Elsevier.

Rubio C., García Á., Cardona F. (2017) Técnicas básicas de microbiología y bioquimica. Madrid: Síntesis.

Ruiz-Gallardo J. R., Paños E. (2017) Primary school students' conceptions about microorganisms. Influence of theoretical and practical methodologies on learning. Research in Science \&o Technological Education, 1470-1138. 
Salas M. (2008) Procesos médicos que afectan al niño en edad escolar. Repercusiones en el entorno educativo. Barcelona: Masson.

Sánchez G., Bernal J. M., García-Estaño R., Guzmán D., Valcárcel M. (2006) Didáctica de las Ciencias Experimentales I. Murcia: DM.

Sender, R., Fuchs, S., Milo, R. (2016). Revised estimates for the number of human and bacteria cells in the body. PLoS Biology, 14(8), e1002533.

Scalas D., Roana J., Mandras N., Cuccu S., Banche G., Marra E., ... Cuffini A. (2017) The Microbiological@mind project: a public engagement initiative of Turin University bringing microbiology and health education into primary schools. International Journal of Antimicrobial Agents, 50, 588-592. 